\title{
Anxiety in Classroom English Presentations: A Case Study in Korean Tertiary Educational Context
}

\author{
Chunguang $\operatorname{Tian}^{1,2}$ \\ ${ }^{1}$ School of Foreign Languages, Binzhou University, China \\ ${ }^{2}$ Department of English Education, School of Education, Chonbuk National University, South Korea \\ Correspondence: School of Foreign Languages, Binzhou University, No. 391, Huanghe $5^{\text {th }}$ Rd, Shandong \\ Province, P.R. China. Tel: 86-186-5439-0516. E-mail: chunguangtian2009@gmail.com
}

Received: December 9, 2018

Accepted: December 28, 2018

Online Published: January 22, 2019

doi:10.5539/hes.v9n1p132

URL: https://doi.org/10.5539/hes.v9n1p132

\begin{abstract}
The purpose of this study is to examine Korean students' anxiety in classroom presentations in tertiary educational context through classroom observation, self-reported questionnaire and semi-structured interview. In the stage of classroom observation, the potential responsivities relating with anxiety were explored through the analysis of fieldwork notes; the questionnaires were filled out by the students after they finished their presentations to unveil the students' perceptions of their anxiety and the causes for such anxiety; the semi-structured interview was carried out to provide further evidence for the above findings. The research participants were twenty two students majoring in English education in a Korean national university. The research findings indicated that Korean students suffered different degree of anxiety in the course of classroom presentations; the major responsivities to anxiety included repeatedly occurring subconscious behaviors, silence, speech disruptions and slow rate of speaking and so forth. Concerning the causes arousing anxiety in classroom presentations, there were four major sources, consisting of negative attitude towards classroom presentations, preparation time, language proficiency, negative feedback from peers, while other factors like making mistakes, attention from audience, and teachers' feedback were not the major source for students' anxiety. These research findings should shed new light on classroom teaching for language teachers to improve their curriculum design to relieve students' anxiety in classroom presentations.
\end{abstract}

Keywords: anxiety, classroom English presentation, Korean EFL learners, Korean tertiary education

\section{Introduction}

Psychologically, anxiety refers to the automatic reactions of nervous system, like tension, apprehension, nervousness and worry (Spielberger, 1983). When people suffer anxiety in social interaction, they show different kinds of physiological responsivities like speech disturbances, periods of silence, a slow rate of speech, flushing face, and repeated gestures (Geer, 1966; Lewin, Jackson, \& McNeil, 1996). These subjective feelings can be detected into the area of language as well, and linguists see anxiety as a state of apprehension or a vague fear in students' language learning (Scovel, 1978). They sought to investigate the causal factors of language anxiety in second language production (Aida, 1994; Horwitz, Horwitz, \& Cope, 1986; Mak, 2011) and different types of anxiety (Scovel, 1978, etc.).

Of all those studies, some centered on the effects of anxiety on the oral performance in language learning (Kleinmann, 1977; Liu, 2006; Samimy \& Tabuse, 1992) and factors causing in-class speaking anxiety (Chen, 2015; Mak, 2011; Woodrow, 2006). King's (2002) study proved that oral presentation could be a beneficial and enjoyable activity for both teachers and students. But generally presentations have been seen as a time-consuming and face-threatening activity that does not help them improve oral proficiency level, and classroom presentations could trigger language anxiety in the classroom, which was the main source for L2 students' silence in presentations in classroom (King, 2002). And getting feedback from peers is regarded as a crucial part in oral activities, especially for presentations, because of interactions between learners and their classmates (Rust, Price \& O'Donovan, 2003). Therefore, getting feedback from peers and teachers turned out to be one source for classroom anxiety in their presentations.

However, the above previous studies were mainly carried out in western contexts or the participants involved 
were Chinese EFL learners. Consequently, there is a paucity of studies on the Korean learners of English in universities in terms of the anxiety in in-class presentations.

This study is conducted to explore the Korean learners' physiological responsivity in in-class presentation in English as a foreign language, and to what extent, these responsivities are related with anxiety and the factors causing such anxiety in classroom presentations in Korean tertiary educational context. Exactly, the research questions are as follows:

(1)What are the Korean university students' perceptions of anxiety in classroom presentation?

(2)What are the responsivities of Korean students' anxiety in classroom presentations?

(3)What are the reasons triggering such anxiety in classroom presentations?

\section{Literature Review}

Anxiety has been explored by psychologists and linguists since the 1970s. In the field of psychological studies, verbal report, physiological responsivity and overt behavior should be considered in assessing fear, anxiety and social phobia. Borkovec, Fleischmann, and Caputo (1973) reported a positive relationship between anxiety related to a social interaction task and speech disturbances. Additionally, Geer (1966) examined the fear of 80 undergraduates from the Introductory Psychology Course at the State University of New York, Buffalo, who were evenly classified as either "high fear" or "low fear" groups based on their responses to The Fear Survey Schedule-II, in speaking followed by a classroom task. He argued that speech disruptions, periods of silence, and a slower rate of speech were more prevalent in high-level speech anxiety subjects than in their low-level anxiety counterparts. The similar findings were further proved by Lewin, et al. (1996), whose introductory psychology participants were classified into three groups by the degrees of anxiety in public speaking and general social interaction. They argued that speech fear and generally social anxious individuals paused more often and for a longer duration than the non-anxious group.

A large number of research findings regarding anxiety from the perspective of psychology have contributed to foreign language teaching. In second language learning and teaching context, there has been an increasing attention given to the anxiety in classroom speaking. Aida (1994) tested Horwitz and associates' construct of foreign language anxiety by adapting Horwitz's FLCAS (Foreign Language Anxiety Scale) in L2 settings. Her results proved the validity of FLCAS, revealing a significant negative correlation between FLCAS scores and final grades among American second-year Japanese Students. Yaikhong and Usaha (2012) developed an EFL Public Speaking Class Anxiety Scale (PSCAS) in Thai context, and the factor analysis results revealed that the PSCAS included the components of communication apprehension, test anxiety, fear of negative evaluation, and comfort in using English in a public speaking class. Second language students suffer different levels of anxiety in speaking classes (Liu, 2006), and five factors causing speaking-in-class anxiety were found in a case study conducted by Mak (2011) based on Foreign Language Classroom Anxiety Scale (FLCAS), saying, speech anxiety, fear of negative evaluation, fear of failing the class, uncomfortableness when speaking with native speakers and negative attitudes towards the English classroom.

Other researchers paid attention to connections between language anxiety and language learning in in-class context (Aida, 1994; Chen, 2015; Kitano, 2001), factors causing L2 students' language anxiety in various language situations (Chen, 2015; Dewaele \& Furnham, 2008; Woodrow, 2006) and strategies to reduce foreign language anxiety (Liu, 2006; Horwitz \& Luo, 2009). Although these factors were analyzed and discussed to deepen understandings of speaking anxiety in general speaking classrooms, the anxieties in classroom presentations as a specific speaking activity, have not yet been systematically explored. Woodrow (2006), on the basis of FLCAS, combined his Second Language Speaking Anxiety Scale (SLSAS) with English for academic purposes (EAP) classes to investigate correlations between second language speaking variables and oral performance based on the facilitating and debilitating effects. The quantitative findings from Woodrow's (2006) research also show that ESL students get anxious about presentations and that the performing in English in front of native speakers or classmates is the most anxious activity for ESL students, but it does not have a significant relationship with their oral performance.

Chen (2015) explored the connections between three Chinese students' speaking-in-class anxiety and their presentation performance and the factors causing oral anxiety during presentations in presentations. He argued that L2 students' anxiety forms mental blocks during presentations, but it has less influence on their presentation performance. As regard the factors causing students to get anxious in presentations, they could be explained and categorized into subjective and objective factors: English proficiency, time for preparation, presenters' experiences, unfamiliar topics, audience attention and some secondary requirements in presentations. 
This study seeks to explore the Korean students' anxiety in classroom presentations through classroom observation, self-reported questionnaire and interview, aiming to find out the responsivity and the causes for anxiety in in-classroom presentations.

\section{Research Methods}

A qualitative case study method (Chen, 2015) was selected to explore the physiological responsivity, connections and factors as regard the Korean EFL learners' speaking anxiety in classroom oral presentations and the primary data in this study were from classroom observation, questionnaire and semi-structured interview. The reason for adopting the qualitative research design was due to the fact that the current study matched the aim of qualitative case study to understand a particular social activity in a particular context, the role and the interaction. First, in the stage of classroom observation, the researcher would take down the field-notes in the classroom where the observation data had been collected. Then, the self-reported questionnaire was distributed the participants to further look into their responsivity, intensity of anxiety and the possible reasons for their anxiety. Next, the semi-structured interview was implemented to provide more evidence for the research findings in the previous two stages.

\subsection{Research Context}

This study was undertaken in English Education Department at a national university in South Korea. The English education major of the university has gained good reputation with high ranking in all the universities across the country.

Language Teaching Methodology course was a compulsory one for all English education majors. This course consisted of two closely related parts: the first part was one credit hour of theory learning on Mondays, and the other part was another one credit hour of classroom presentation for students on Wednesdays. At the end of the semester, the score of the students' classroom presentation would be calculated in their final grades. In the latter part, every week three students were supposed to make presentations of the teaching methodologies that had been learnt on Mondays' lesson. This study focused on the latter part of the course, in which at the beginning of the classes, the professor would check the attendance of the students, and then assigned the learning tasks for the next week; after that, the students started their presentations. It was actually a 15-minute microteaching. The whole process of the presentations was recorded with the students' hand phones and evaluated by the professor as well as all the peer students through written feedbacks. Whenever it was necessary, the presenters would distribute some handouts to their peers.

The coursework was given in a multimedia classroom, where there was a central console with a computer and an electronic display screen on the wall in front of the classroom. The total 20 students were divided into five groups, gathering around tables in the classroom. Every time they had lessons on Wednesdays, it could be easily seen that some students would bring their presentation materials and rehearsed with their teams or partners.

The professor of this course, Ms. K was a newly-recruited staff in September, 2017, who graduated from a U.S university. And it was her first semester and first time to give lectures on language teaching methodology, yet her research interest included qualitative-based language teaching research.

\subsection{Participants}

The subjects in the current study were twenty sophomores from the same class in English Education Department, including four males and eighteen females, participated in this study. They shared similar cultural background, that is, they were born and raised in Korea and learnt English as a foreign language. The research participants were supposed to complete the same course entitled English Language Teaching Methodology, which was a mandatory module for English Education majors. The demographic information of the participants could be seen from Table 1 (Because in the stage of quantitative data collection, two students did not complete the questionnaire, their demographic information was not given here).

Table 1. The profile of the participants

\begin{tabular}{cccccc}
\hline \multicolumn{2}{c}{ Gender } & \multirow{2}{*}{ Age } & \multirow{2}{*}{ Years of English Learning } & \multicolumn{2}{c}{ overseas experience } \\
\cline { 1 - 3 } Male & Female & & & Yes & No \\
\hline 4 & 16 & $21 \sim 29$ & $12 \sim 19$ & 4 & 16 \\
\hline
\end{tabular}

\subsection{Research Instruments}

The fieldwork notes were adopted to collect qualitative data in the classroom presentations. The fieldwork notes included three parts: the first part was the detailed information about the note-taking, including name of the 
observer, date and time of the observation, general settings of the fieldwork, people involved and other information that was necessary to be stated; the second part was the classroom observation notes; and the third part was observational comments.

The questionnaire was adapted from Foreign Language Classroom Anxiety Scale (FLCAS) (Horwitz et al, 1986), consisting of twenty two questions. These 22 items would be measured on a six-point Likert scale ranging from "strongly disagree" (coded 1) to "strongly agree" (coded 6). Among all the items, 12 items were to measure the causes for classroom speaking anxiety and 10 more items to measure the perceptions of anxiety. The details of the questionnaire could be seen from the attached Appendix I at the end of the article.

The semi-structured interview was carried out based on the findings in fieldwork notes, including the observational comments. Through the interview, the relationship between the anxiety and physiological responsivities was explored, as well as the causes for such anxieties.

\subsection{Data Collection}

The researcher visited the class and did classroom observations on Wednesday weekly. In the course of classroom observations, the researcher took down fieldwork notes for the sake of observing the students' behaviors in terms of verbal and non-verbal responsivities in their classroom presentations of micro-teaching. In terms of observation notes, the whole process of the classed was recorded through note-taking, particularly the students' behaviors in their presentations; for the part of observational comments (O.C.), any interesting physiological responsivities were marked for later analysis.

The questionnaires were distributed to the students face-to-face just after they have finished their classroom presentations because they remembered their own situation clearly at that moment. The participants were told that this survey was just for academic research and all the results of the questionnaires would be confidential to their professors. After the student has completed the questionnaire, it would be submitted to the researcher immediately.

The semi-structured interview was for the focal studies of the students who showed certain typical behavioral patterns in their presentations, to further support the findings from classroom observations and questionnaires. It was adopted to elicit the degree of the students' anxiety and the causes for such anxiety. The interview was carried out when the coursework was finished and the teacher has left the classroom. The researcher interviewed the participants who had been told that all the answer to the questions would be confidential to their teachers and be for the purpose of scientific research. Having got the permission of the participants, all the interviews were recorded.

\subsection{Data Analysis}

First, all the fieldwork notes were translated in Word Documents and read repeatedly by the researcher so that some recurring patterns possibly related with anxiety would be identified.

Following this, the data on the questionnaires was input to Excel spreadsheet for further analysis with SPSS 13.0, after having collected all the questionnaires. The questionnaire could be split into two categories: perceptions of anxiety and causes for anxiety. In terms of the causes for anxiety, three more subcategories were further distinguished, that is, attention from the audience, number of presentations, preparation, teacher feedback and making mistakes. The average score of the 22 items would be calculated.

Then, when the 22 recorded interview audios have been collected, all the files were transcribed and recorded manually by the researcher and stored in the format of Word Documents separately. The text files were coded manually to annotate those findings related with the research questions regarding the intensity of anxiety, the responsivities and the causes for anxiety in classroom presentations.

\subsection{The Role of the Researcher}

The motivation that drove the researcher to focus on this topic was the coursework entitled Qualitative Research in Language Teaching, lectured by Ms. K when the researcher pursued doctorate degree in South Korea. Ms. K encouraged us to join her classes and tried writing fieldwork notes for a small case study. Although it is a routine for doctorate students to do classroom presentations, yet it accounted for much stress and sufferings. The researcher's personal experience and intuition suggested that classroom presentations made the students anxious and nervous and there were many factors contributing to the students' anxiety including language proficiency, gender and life experience. Thereafter, the researcher joined Ms. K's classes, who decided to keep an eye on the students' feelings during their presentations and to study the possible reasons for their anxiety.

When the researcher was a doctorate student, there were some communications and talk between the researcher 
and those undergraduate students who enrolled Ms. K's Language Teaching Methodology course. Therefore, the researcher's attendance to their classroom would not take any impacts on their classroom behaviors because we knew each other well, so much so that the questionnaire and the interviews were both implemented in a relaxed and friendly atmosphere, which guaranteed that all the collected data could reflect their true situations.

\section{Results and Discussions}

\subsection{Results of the Questionnaire}

The questionnaires were distributed to the 22 participants by the researcher during the class time and were collected after the class. The response rate was 100 percent. But two participants did not give any information on gender; additionally, neither did they complete the questionnaire, leaving 11 items blank, so only 20 valid questionnaires were included in the final analysis.

\subsubsection{The Perceptions of Anxiety}

The first research question can be examined through the questionnaire survey. Table 2 displays the different scores of students self-reporting on ten items about the perceptions of anxiety on the questionnaire.

From Table 2, it could be seen that except Item 14, the average scores of all the items were above 3, ranging from 3.35 to 4.7 , which meant that all the twenty participants suffered nervousness to different degrees in their presentations in classroom. The highest average score went to Item 20 with 4.7 points, which implied that the students would feel relaxed when they completed their presentations; Item 2 got the average 4.6 points, which implicated that classroom presentations were more anxiety-raising activity than other classroom activities. Item 16 was given an average 4.05 points, implying that the Korean students could feel heart pounding which was an indicator of high-level anxiety. However, Item 14 was only rated an average 2.8 points, which seemed to contradictory with Item 16. This might contribute to the students' misunderstanding of this item. Intuitionally, when a person was in high level of anxiety, they would feel like a different person.

One more interesting result was that Item 6, "I made a full preparation for my presentation", got a relatively high score of 4.25 , which suggested that even if the students were well prepared, they were still anxious during making presentations.

Table 2. Perceptions of anxiety in classroom presentation

\begin{tabular}{lll}
\hline \multirow{2}{*}{ No. } & Item & $\begin{array}{l}\text { Average } \\
\text { Score }\end{array}$ \\
\hline 20 & I am usually at ease after finishing my presentation in the class. & 4.7 \\
2 & I feel more tense and nervous about the presentation than other class activities. & 4.6 \\
6 & I made a full preparation for my presentation. & 4.25 \\
16 & I can feel my heart pounding when I give the presentation. & 4.05 \\
15 & In the presentation, I may get so nervous that I forget what I know. & 3.85 \\
13 & Sometimes I can't express my true feelings and thoughts in English after I make mistakes in & 3.7 \\
5 & my presentation, and this situation makes me uncomfortable. & 3.55 \\
3 & I worry that I cannot make a good presentation. & 3.5 \\
18 & I feel overwhelmed, because I have to learn the rules about how to give a good presentation. & 3.35 \\
14 & am. & \\
\hline
\end{tabular}

\subsubsection{Causes Informing of Anxiety in Classroom Presentations}

For the causes of the anxiety in classroom presentations, there were five factors attributed to the anxiety in classroom presentations, namely, number of presentations, making mistakes, preparation, attention from the audience and teacher's feedback, as were shown in Table 3.

In terms of the number of presentations, Item 4 with the average score 4.4 , showed that the students displayed a relatively high degree of anxiety if they were required to do presentations more than once in class. This may be contributed to the reason that making presentations was a time-consuming task and not favored by the students. Korean students hate to do such classroom activities like presentations.

Whether being afraid of making mistakes account for students' anxiety in presentation could be tested by Item 12 , which only got 2.7, much less than the other items in the questionnaire. It is argued that being afraid of making mistakes was not a major source informing of the anxiety in Korean students' classroom presentations. 
Regarding the time of preparation in presentation, the students reported a high score for Items 8 and 9 with 4.85 and 4.3 respectively, and a relatively lower score of 3.45 on Item 7. The comparison between Item 7 and 8 proved that Korean students suffered high-level anxiety in their presentations because although the students had a good preparation for their presentations, they displayed a high degree of anxiety, not mentioning without good preparation. This also corresponded to the high score of Item 5 and Item 6 in the previous part. The students preferred to make full enough preparation for their presentations, worrying about their preparing not enough. Besides, by examining the average score of Item 9, it could be inferred that the students suffered extreme nervousness because they knew they trembled when they realized that they would be the next one to make the presentation. Therefore, preparation did matter, causing Korean students' anxiety in classroom presentations.

Considering the factor of teacher's feedback, there were four items (Items 10, 11, 21 and 22) examining the effects of teacher's feedback on students' anxiety in classroom presentations. The scores of Items 10, 11 and 22 were $3.8,3.2$ and 3.05 respectively, slightly higher than 3 , suggesting that the students did not worry about getting negative feedbacks from their teacher and this may contributed to the reason that teacher's feedback would not influence their final grade in this course. Moreover, the high score of Item 21 also told us that the students really looked forward to gaining teacher's praise for their presentations, which could make them feel relaxed and happy. Consequently, it can be concluded that teacher's feedback does not result in students' anxiety in classroom presentations.

The last cause for classroom anxiety was the attention from the audience. Item 1 and Item 17, which only got 3.15 and 3.5, slightly higher than 3, indicated that speaking in front of the public is not a major source for students' anxiety in classroom presentations for Korean university students. Therefore, speaking in the public or the general anxiety in public speaking is a potential factor, not the major source of students' anxiety making classroom presentations. This point could also be proved by the lowest score of Item 19 with 2.2, which indicated that making presentations in class or speaking in the public may not be so face-threatening, because they were not afraid of being laughed at by their peer classmates in classroom.

Table 3. Causes for anxiety in classroom presentations

\begin{tabular}{llll}
\hline No. & \multicolumn{1}{c}{ Item } & \multicolumn{1}{c}{ Factors Category } & Average Score \\
\hline 4 & $\begin{array}{l}\text { It worries me when I know I need to give multiple } \\
\text { presentations in the class. }\end{array}$ & Number of presentations \\
12 & $\begin{array}{l}\text { I don't worry about making mistakes when I give the } \\
\text { presentation. }\end{array}$ & Making mistakes \\
8 & $\begin{array}{l}\text { I start to panic when I give the presentation without } \\
\text { enough preparation. }\end{array}$ & Preparation \\
9 & $\begin{array}{l}\text { I tremble when I know that I will be the next one to give } \\
\text { the presentation. }\end{array}$ & Preparation \\
7 & $\begin{array}{l}\text { I start to panic before the presentation even if I have a } \\
\text { good preparation for it. }\end{array}$ & 3.4 \\
21 & $\begin{array}{l}\text { After the presentation, I feel relaxed and happy when the } \\
\text { teacher praises my performance. }\end{array}$ & Teacher feedback \\
10 & $\begin{array}{l}\text { It frightens me when I know the in-class presentation will } \\
\text { be graded by the teacher. }\end{array}$ & Teacher feedback \\
11 & $\begin{array}{l}\text { I'm afraid that my teachers tend to give negative } \\
\text { feedbacks after my presentation. }\end{array}$ & Teacher feedback \\
22 & $\begin{array}{l}\text { I get upset when I don't understand the teacher's specific } \\
\text { feedback on my presentation. }\end{array}$ & Teacher feedback \\
17 & $\begin{array}{l}\text { When giving presentation, I often stutter or repeat words } \\
\text { when the teacher and other classmates gaze at me. }\end{array}$ & Attention from the audience \\
1 & $\begin{array}{l}\text { I feel very self-confident about speaking English in front } \\
\text { of other students. }\end{array}$ & Attention from the audience \\
19 & $\begin{array}{l}\text { I am afraid that the other students will laugh at me when I } \\
\text { give the presentation. }\end{array}$ & Attention from the audience \\
\hline
\end{tabular}

\subsection{Results of Classroom Observation and Interview}

More evidence from fieldwork notes in classroom observation as well as observational comments would be presented in this part to explore the Korean EFL learners' physiological responsivities of and the causes for 
anxiety in classroom presentations. The results from the semi-structured interview were to confirm the findings in classroom observations or possibly to shed new light on language learners' perception of anxiety and the causes informing of their anxiety.

\subsubsection{Physiological Responsivity-recurring Behaviors from Fieldwork Notes and Observational Comments}

After having carefully read and coded the fieldwork notes and the observational comments, three students displayed some recurring patterns in their classroom presentations. These features would be analyzed to examine the students' perceptions of anxiety and the possible factors contributing to their anxiety.

One student (ID:01) showed some typical physiological responsivities including some overt behaviors, like scratching hair and smiling. But these behaviors could be subconsciously, in other words, the students may even not notice their behaviors.

... Standing in the front of the classroom she began to scratch her hair overhead, and the hair near the right temple and ear, and then the hair of the left ear, and this scratching repeated three times.... During the first two minutes she still scratched her hair from time to time. ... I noticed that every time when she asked her peers to answer the questions on the handout she smiled... her index finger whirled with a moment of pause in the air and she smile once more [Student1, female undergraduate, From fieldwork notes]

In the course of her presentation, she showed some repeatedly occurring behaviors like the above ones, which have been ratified that these were indicators of anxiety through the interview with the student,

"I don't know I scratched my hair, hh...I am too nervous so that I didn't realized that... ", “...I am nervous. When I am nervous, I smile”. [Student1, female, from informal interview]

But, when I asked her other feelings related with anxiety or fear, such as fast heart pounding and quick breathing, she responded me with "no".

Another student (ID:04) exhibited other linguistic signs like slow speech and grammatical errors besides some physical responsivities like scratching head, which could be easily seen in the following fieldwork notes,

"...The presenter walked slowly towards the front of the classroom. After he was standing still, he began to scratch his head, and started talking while walking back and forth. Besides, he brought a bag of candy and put them on the desk. He made a simple self-introduction and made clear what his presentation was about first. He spoke slowly and sometimes with grammatical errors/mistakes". [Student 4, female, from fieldwork notes]

"...When each group finished the practice, they would be given a candy as a reward. Finally, the presenter asked all the students whether they could recite the short dialogue. And two groups were selected for recitation, both of which were rewarded with candies (even if one group made some mistakes, candies were also given, but without any corrections for the mistake.) "[Student 4, female, from fieldwork notes]

In her interview, she answered, “...I am too nervous that I forgot some words. So I speak slowly because I have to think of the words.... I can't understand what they are talking about, so I can't realize their mistakes, and I just gave them candies as the rewards, ...yeah, yes, I, I am too nervous."

Therefore, as far as this student is concerned, anxiety resulted in some misbehavior like speaking slowly and inappropriate classroom management.

One more student (ID:03) also unveiled similar behaviors as the previous student (ID:04). From the classroom observation, the student usually spoke slowly or displayed repetition of words, short periods of silence etc.

She spoke slowly and with a moment of silence, smiled. ..., she repeated the same requests twice. Besides, while speaking, her index finger spun, then with a moment of pause.... [Student 3, female, From fieldwork notes]

"The presenter spoke relatively slow. And while speaking, he looked around the whole class, seemingly to ask for any feedback from the students. "[Student 3, female, from observational comments in fieldwork notes]

In the course of interview, she responded, “...yes, I am nervous and my mind came into a blank, so I forgot what I wanna say, then I smiled, and smiled. When I whirled my figure, I am thinking about what I should say,...I forgot something because of my nervousness, ..."

The above findings from fieldwork notes and interviews are, to some extent, consistent with the previous research findings that there exists a positive relationship between anxiety and speech disturbances (Borkovec, Fleischmann, \& Caputo, 1973). And speech disruptions, periods of silence, and a slower rate of speech were more prevalent in high-speech anxiety subjects (Lewin, et al., 1996). 


\subsubsection{Causes for Anxiety in Classroom Anxiety}

After the participants having their informal interviews, they told the researcher the reasons for being anxious / nervous in the course of presentation. Some typical excerpts have been selected here to unveil these reasons for the students' anxiety in their classroom presentations.

"I am not fully prepared for the presentation,... I am not confident about my English. My English isn't good, ... I can't speak English as well as another student..., I am afraid that I will get some negative feedback because of comparison with another student, although the feedback won't affect my grade." [Student1, a female undergraduate, English Education Major, From informal interview]

“...honestly, I don't think I am not afraid of becoming the focus of the class. I am nervous because I am not confidents of my English proficiency,...I really hate classroom presentations because I have to spend much time and efforts on preparation. And even if I have fully prepared for it, I still feel extremely nervous when I made the presentation....in fact, I don't worry that the teacher will make some negative comments on my presentation, because that won't influence my final assessment." [Student 3, female, From informal interview]

“....yes, I am fully prepared, but when it is to be my turn to make presentation, I begin to tremble, because I am very nervous; I am fearful that I can't speak English fluently and my classmates do better than me. I feel stressful when they compare my classmates and me. But I won't be frightened by making mistakes. Everybody make mistakes when they speak a foreign language,....yes, yes, I am nervous, so I breathe a sigh of relief when my presentation was finished." [Student 4, female, From informal interview]

From the above interview transcripts, it was easy to figure out the factors accounting for Korean students' anxiety in classroom presentations. These factors included preparation, English language proficiency, comparison from peers and classmates, negative feedbacks from such comparisons, reluctance to make classroom presentations and negative attitudes towards classroom presentation activities. Some of these findings corresponded to that of Mak (2011) who argued that fear of negative evaluation, fear of failing the class, uncomfortableness were causes for speaking-in-class anxiety. And getting feedback from peers is regarded as a crucial part in oral activities, especially for presentations, because of interactions between learners and their classmates (Price \& O’Donovan, 2003).

However, some other factors contributing to the students' anxiety in their classroom presentations were also detected like English language proficiency, comparison among classmates and the negative feedbacks that resulted from such comparisons.

\section{Conclusion}

The conclusion of the current study may be limited by it small sample size, the curriculum design and assessment, yet it still can contribute to the understanding the Korean university students' anxiety in classroom presentations. It has been found that the Korean participants showed different degrees of anxiety in their presentations. The anxiety would be intensified when they did not make a full preparation for their presentations. Additionally, the causes for such anxiety in classroom presentations could be classified into five aspects: attention from the public, times of the presentations, preparation time, peer feedback and language proficiency. The Korean students are particularly frightened by receiving negative feedback from their peer classmates because of the possible comparisons in language proficiency. In addition, it is also suggested that being afraid of making mistakes is not a major source for anxiety, which also implies that Korean students do not consider classroom presentation as a face-threatening activity. A correlation between anxiety and such physiological responsivities like smiling, speech disturbances and silence were found. Unexpectedly, some obvious behaviors like scratching hairs, clapping hands that were considered by the researcher to be caused by anxiety could not be proved in the interview because they even did not notice that they had such behaviors. In light of these findings, it needs more delicate equipment to test whether there exists certain relationship between the participants' explicit behaviors and their anxiety.

The present study is also limited by the short duration of classroom observation and interview. Longer time of classroom observation and more interviews will help to find better patterns of behaviors in classroom presentations, and in-depth interviews will help to find out the scale of their anxiety and the relationship between anxiety and physiological behaviors. Of course, if possible, in the future study, the medical instruments can be carried with the presenter doing presentations to measure the blood pressure and pulse etc. to better explain such a relationship. But there may be a potential risk that it will make our participants more anxious and nervous when carrying these instruments. Anxiety is still a challenging topic, deserving our attention and efforts for further studies to provide more pedagogical instructions for our students to have a better performance in their 
classroom presentations.

\section{References}

Aida, Y. (1994). Examination of Horwitz and Cope's construct of foreign language anxiety: The case of students of Japanese. Modern Language Journal, 78(2), 155-67. https://doi.org/10.1111/j.1540-4781.1994.tb02026.x

Borkovec, T. D., Fleischmann, D. J., \& Caputo, J. A. (1973). The measurement of anxiety in an analogue social situation. Journal of Consulting and Clinical Psychology, 41(1), 157-161. http://dx.doi.org/10.1037/h0035579

Chen, Y. (2015). ESL Students' Language Anxiety in In-Class Oral Presentations. Theses, Dissertations and Capstones. Paper 962.

Dewaele, J. M., Petrides, K. V., \& Furnham, A. (2008). Effects of trait emotional intelligence and sociobiographical variables on communicative anxiety and foreign language anxiety among adult multilinguals: A review and empirial investigation. Language Learning, 58(4), 911-960. https://doi.org/10.1111/j.1467-9922.2008.00482.x

Geer, J. H. (1966). Effect of fear arousal upon task performance and verbal behavior. Journal of Abnormal Psychology, 71(2), 119-123. https://doi.org/10.1037/h0023098

Horwitz, E. K. M. T., \& Luo, H. (2009). Foreign language anxiety. In J. C. Cassady (edu.), Anxiety in schools: The causes, consequences, and solutions for academic anxieties. New York: Peter Lang.

Horwitz, E. K., Horwitz, M. B., \& Cope J. A. (1986). Foreign language classroom anxiety. Modern Language Journal, 70(2), 125-132. https://doi.org/10.1111/j.1540-4781.1986.tb05256.x

King, J. (2002). Preparing EFL learners for oral presentations. Dong Hwa Journal of Humanistic Studies, 4, 401-418.

Kitano, K. (2001). Anxiety in the college Japanese language classroom. The Modern Language Journal, 85, 549-566. https://doi.org/10.1111/0026-7902.00125

Kleinmann, H. H. (1977). Avoidance Behavior in Adult Second Language Acquisition'. Language Learning, 27(1), 93-107. https://onlinelibrary.wiley.com/doi/10.1111/j.1467-1770.1977.tb00294.x

Lewin, M. R., Jackson, G. D., \& McNeil, D. W. (1996). Avoidance, escape, and subtypes of social anxiety. Manuscript submitted for publication.

Liu, M. H. (2006). Anxiety in Chinese EFL students at different proficiency levels. System, 34(3), 301-316. https://doi.org/10.1016/j.system.2006.04.004

Mak, B. (2011). An exploration of speaking-in-class anxiety with Chinese ESL learners. System, 39(2), 202-204. https://doi.org/10.1016/j.system.2011.04.002

Rust, C., Price, M., \& O'donovan, B. (2003). Improving students' learning by developing their understanding of assessment criteria and processes. Assessment and Evaluation in Higher Education, 28(2), 147-164. https://doi.org/10.1080/02602930301671

Samimy, K. K., \& Tabuse, M. (1992). Affective variables and a less commonly taught language: a study in beginning Japanese classes. Language Learning, 42(3), 377-398. https://doi.org/10.1111/j.1467-1770.1992.tb01341.x

Scovel, T. (1978). The effect of affect on foreign language learning: A review of the anxiety research. Language Learning, 28, 129-142. http://dx.doi.org/10.1111/j.1467-1770.1978.tb00309.

Spielberger, C. D. (1983). Manual for the state-trait anxiety inventory. Palo Alto, California: Consulting Psychological Press.

Woodrow, L. (2006). Anxiety and speaking English as a second language, RELC Journal, 37(3), 308-328. https://doi.org/10.1177/0033688206071315

Yaikhong, K., \& Usaha, S. (2012). A Measure of EFL Public Speaking Class Anxiety: Scale Development and Preliminary Validation and Reliability. English Language Teaching, 5(12), 23-35.

http://dx.doi.org/10.5539/elt.v5n12p23 


\section{Appendix I: The Interview Questionnaire}

\section{ANXIETY IN IN-CLASS PRESENTATIONS QUESTIONNAIRE}

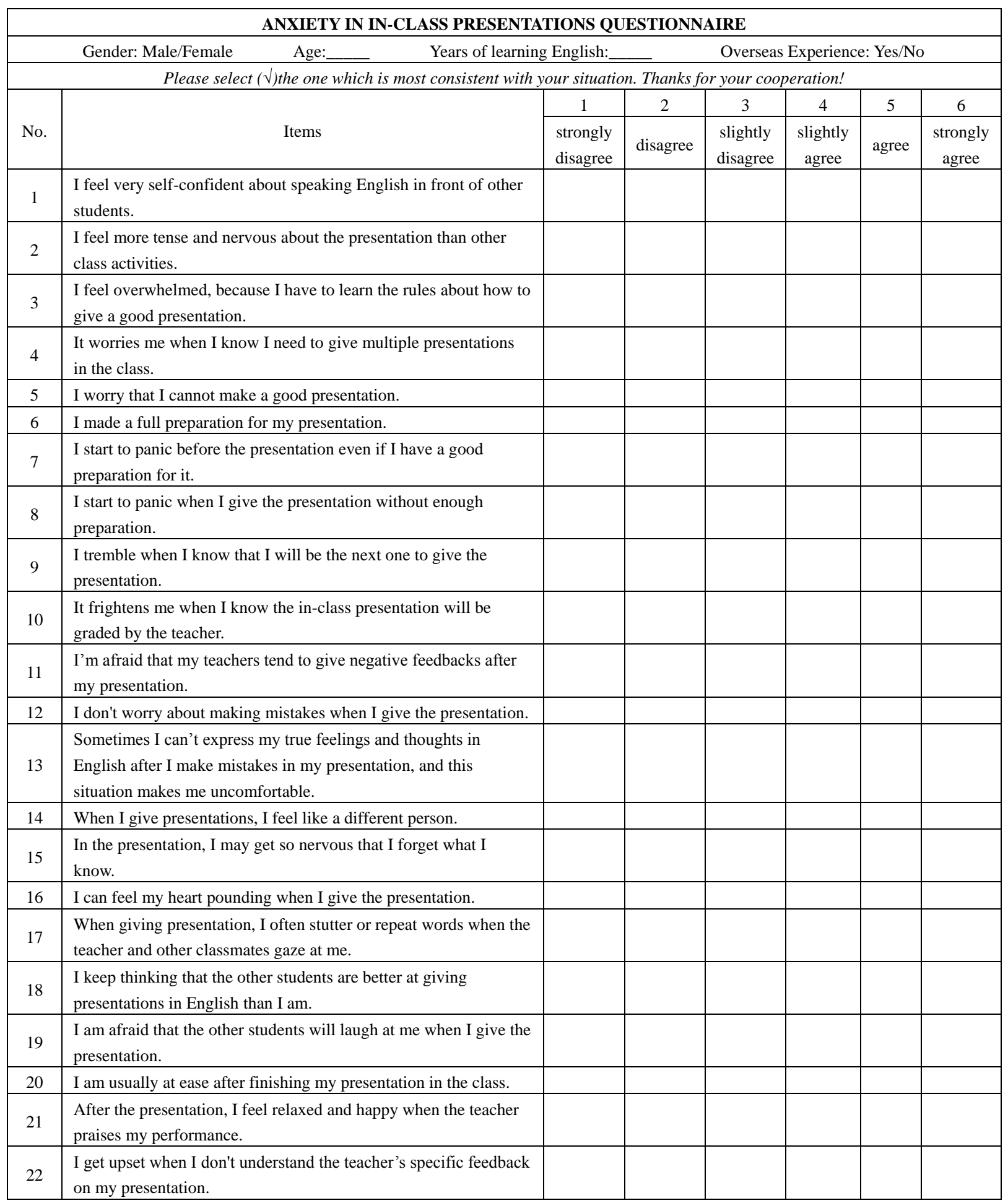

\section{Appendix II: A Sample of the semi-structured interview (R stands for Researcher While $S$ stands for Student.)}

【Date: 15th Nov, 2017】

R: Hello! Can I have a short talk with you?

S: (Nodded) Yes, ok. 
R: How do you feel while you standing in front of the classroom?

$=\mathrm{S}$ : (Eyes blanked, seemingly not understand my question)

I mean, do you feel nervous or anxious when you are making your presentation?

S: Yes, yes, I am very nervous.

R: Did you fully prepared for your presentation?

S: No, I didn't. I am not fully prepared for the presentation.

R: So you're very nervous.

S: Yes.

$\mathrm{R}$ : Is there any other reasons for your nervousness?

S: I am not confident about my English. My English is not good. Her English is very good. (pointing to the other presenter) I am afraid of ....(She asked her classmate next to her in Korean) comparison. I am afraid that I will get some negative feedback because of comparison with another student.

$\mathrm{R}$ : Will the feedback influence your grade of the course?

S: No.

R: I noticed that during your presentation, you are always touching your hair, overhead, and the hair near the right temple and ear, and then the hair of the left ear, again and again. Why do you..?

S: Really? I don't know I scratched my hair, hh. (Smiled)

R: And I also noticed that you were always smiling while making presentation. Why?

S: I am nervous. When I am nervous, I smile.

R: So you smile because you're nervous. Any other things when you are nervous? For example, do you feel your heart pounding, or quick breathing?

S: No, I didn't.

R: Ok, thanks for your time.

\section{Appendix III A sample of fieldwork note}

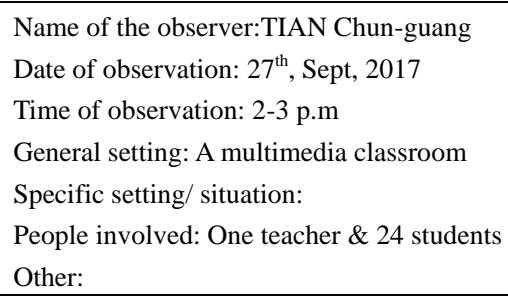

(Classroom settings) This is a multimedia classroom, where total 27 students are divided into six groups, gathering around tables in the classroom, with their textbooks on the tables. Before the start of the lesson, all the students were talking: some were preparing their presentations (which can be seen from the teaching aids on their hands); others were reading the textbooks or playing with their cellphones. A few students came late after the beginning of the class.

\section{(Class observation)}

Before the students' presentation, the teacher allocated the assignment for the next week. Because each chapter will be distributed to a limited number of students and more than wanted students are willing to do the same chapter, the final decision is based on the finger-guessing game. After that, the teacher checked the presence of all the students. (This procedure lasted about 10 minutes) 
(The first presentation by a female student started from $2: 12$ to $2: 22$, lasting ten minutes. The teaching content is a short conversation between two new students in the beginning of the semester.)

The whole process of the presentation

The presenter walked to the front of the classroom and announced the start of the presentation, and then she introduced the main content for the presentation on audio-lingual teaching method. The dialogue was between a girl and a boy.

The presenter read the dialogue twice and while reading, she reminded the students of the different speeches including pronunciation and intonation by different roles. Next, the video was shown to the students, who were required to listen to the dialogue carefully; and then, it was followed by a listen-and-repeat cycle: the presenter read and the students followed with a relatively slow speed for the first time and a normal speed for the second time. Every time when the students finished repeating, the presenter would give some feedbacks like "good", "well done" etc. In this procedure, the presenter still reminded the students of paying attention to the intonation as well as some specific words and their intonation.

Next step was a role-play for three-times repetition of the dialogue: for the first time the presenter played the role of the boy, and all the students the girl; for the second time, all the students were divided into two groups with different roles randomly, and then the dialogue was repeated; for the third time, the students were divided into two groups, male and female, who repeated the according speeches respectively.

The last step for her presentation was grammar: the sentence pattern "Have we ever met ..." was attached great importance and the presenter made several sentences with this pattern for students to understand its use. Finally, some handouts were distributed to all the students to review the teaching content and related grammatical item. At the end of the presentation, the presenter also asked the students whether there was any problem to make sure that all the students could follow the flow of her lesson.

During the whole process of the presentation, the presenter spoken English fluently and she clapped her hand when it came to some important issues like the pronunciation and intonation of the words and when it came to the transitional position from one teaching step to the next one.

(The second presentation by a male student started from 2:28 to 2:42, lasting 14 minutes. The teaching content is also a short conversation.)

The presenter walked slowly towards the front of the classroom. After he was standing still, he began to scratch his head, and started talking while walking back and forth. Besides, he brought a bag of candy and put them on the desk. He made a simple self-introduction and made clear what his presentation was about first. He spoke slowly and sometimes with grammatical errors/mistakes.

The whole process of the presentation

First the presenter read the short dialogue and all the students listened to him carefully.

Then he read the dialogue sentence by sentence first and the students followed him, and this was repeated twice. And then another round of repetition, the presenter read first and all the students followed.

The students were grouped randomly and role played the dialogue watching the script. (During this process, the presenter walked around and talked to the students without any partner.

Then, the presenter asked some groups of volunteers to repeat the dialogue sentence by sentence. When each group finished the practice, they would be given a candy as a reward.

Finally, the presenter asked all the students whether they could recite the short dialogue. And two groups were selected for recitation, both of which were rewarded with candies. (even if one group made some mistakes,

candies were also given, but without any corrections for the mistakes.)

\section{Copyrights}

Copyright for this article is retained by the author(s), with first publication rights granted to the journal.

This is an open-access article distributed under the terms and conditions of the Creative Commons Attribution license (http://creativecommons.org/licenses/by/4.0/). 